\title{
Antihypertensive drugs and erectile dysfunction as seen in spontaneous reports, with focus on angiotensin II type I receptor blockers
}

This article was published in the following Dove Press journal:

Drug, Healthcare and Patient Safety

27 March 2010

Number of times this article has been viewed

\author{
Elisabet Ekman' \\ Staffan Hägg ${ }^{2}$ \\ Anders Sundström ${ }^{3}$ \\ Viktoria Werkström' \\ 'Regional Pharmacovigilance \\ Unit, Clinical Pharmacology, \\ Lund University Hospital, Lund, \\ Sweden; ${ }^{2}$ Division of Clinical \\ Pharmacology, Linköping University, \\ Linköping, Sweden; ${ }^{3}$ Centre for \\ Pharmacoepidemiology, Karolinska \\ Institute, Stockholm, Sweden
}

Aim: To describe spontaneously reported cases of erectile dysfunction (ED) in association with angiotensin II type I blockers (ARB) and other antihypertensive drugs.

Subjects and methods: All spontaneously reported cases of ED submitted to the Swedish Medical Products Agency (MPA) between 1990 and 2006, where at least one antihypertensive drug was the suspected agent, were scrutinized. Patient demographics, drug treatment and adverse reactions were recorded. Using the Bayesian Confidence Propagation Neural Network (BCPNN) method, the information component (IC) was calculated.

Results: Among a total of 225 reports of ED, 59 involved antihypertensive drugs including ARB (9 cases) as suspected agents. A positive IC value was found indicating that ED was reported more often in association with antihypertensive drugs classes, except for angiotensin-converting enzyme inhibitors, compared with all other drugs in the database. Positive dechallenge was reported in 43 cases $(72 \%)$.

Discussion: All classes of major antihypertensive drugs including ARB were implicated as suspected agents in cases of ED. Few risk factors were identified. The relatively high reporting of ED in association with ARB is in contrast with previous studies, suggesting that ARB have neither a positive nor any effect on ED. This discrepancy suggests that further studies are warrnted on this potential adverse reaction to ARB.

Keywords: adverse drug reaction, spontaneous reporting, antihypertensive drugs, angiotensin II type 1 receptor blockers, erectile dysfunction

\section{Background}

Erectile dysfunction (ED), ie, the consistent or recurrent inability of a man to attain and/or maintain penile erection sufficient for sexual activity, ${ }^{1}$ is a common disorder with a reported prevalence between $13 \%$ and $46 \%$ in the general population and with an exponential increase in occurrence from 60 years of age. ${ }^{2}$ Various medical, psychological and lifestyle factors have been implicated in the pathogenesis. Diabetes, hypertension, hyperlipidemia, obesity, smoking, and lack of physical activity are established risk factors for ED. ${ }^{3}$

Drugs can have adverse effects on sexual function in several dimensions: central effects by sedation and loss of libido, central and peripheral effects by influencing neurotransmitters and receptors. ${ }^{4}$ Use of antihypertensive drugs has been associated with $\mathrm{ED}^{5}$ although the relationship has been disputed. ${ }^{6}$ Diuretics and adrenergic beta-antagonists (beta-antagonists) have been reported to have negative outcomes on various endpoints regarding sexual function. Calcium channel blockers (CCB) and angiotensin-converting enzyme (ACE) inhibitors have not been associated with major
Correspondence: Elisabet Ekman Regional Pharmacovigilance Unit, Clinical Pharmacology, University Hospital, S - 22I 85 Lund, Sweden

Tel +46 46I75380

Fax +464621I1987

Email elisabet.ekman@med.lu.se
Drug, Healthcare and Patient Safety 2010:2 2I-25

(C) 2010 Ekman et al, publisher and licensee Dove Medical Press Ltd. This is an Open Access article which permits unrestricted noncommercial use, provided the original work is properly cited. 
negative impact on ED. It has also been suggested that angiotensin II type 1 receptor blockers (ARB) would affect sexual function less than other antihypertensive treatment. ${ }^{2,7}$ Some data even suggest that sexual function and ED may improve during treatment with ARB. ${ }^{8-10}$

In view of the fact that studies are lacking, limited information is available from daily clinical practice, and ARBs may differ in this respect from other antihypertensive drugs, we wanted to study spontaneous reports of ED for different groups of antihypertensive drugs. In addition, we wanted to characterize cases of ED in terms of risk factors.

\section{Methods}

To study reports from clinical practice on ED during treatment with antihypertensive drugs, we reviewed spontaneous reports in the Swedish adverse drug reaction (ADR) database (SWEDIS). The groups of antihypertensive drugs were identified according to their ATC code (Anatomic Therapeutic Chemical classification) as defined by the WHO Collaborating Center for Drug Statistics Methodology. ATC C03A (thiazide diuretics), $\mathrm{C} 07 \mathrm{AA}$ and $\mathrm{AB}$ (beta-antagonists), C08 (CCB), C09A (ACE inhibitors), and C09C (ARB) were included. According to the Swedish Medical Products Agency's (MPA) code of statutes, it is mandatory for health care professionals to report serious reactions, new and unexpected reactions and also those ADRs that seem to increase in frequency. For new drugs reporting of all adverse effects except those labeled as common in the Summary of Product Characteristics (SPC) is encouraged. An ADR is defined by the World Health Organization (WHO) as "a response to a drug which is noxious and unintended, and that occurs at doses normally used in humans for the prophylaxis, diagnosis, or therapy of disease or for the modification of physiological function".

All cases of suspected ED associated with antihypertensive drugs reported to SWEDIS during the period 1990 to 2006 were identified and studied. In SWEDIS the following information can be obtained in addition to the suspected drug and the ADR: age, sex, concomitant medication, treatment dates, indication for treatment, concurrent diseases, dosage, and outcome of the reaction. Most reports also have a narrative. Drugs can be listed as being suspected of having caused the reaction, as interacting with another prescribed drug, or as concomitant medication not related to the ADR. Each report can include more than one ADR and/or suspected drugs. The causality of the suspected ADR is classified using WHO criteria (WHO Technical Report no 498, 1972). The reports are handled at regional centers situated at six university hospitals by an expert panel consisting of clinical pharmacologists and specially trained nurses and pharmacists. Thereafter the cases are re-evaluated at a national level by the MPA.

From the case reports the following information was collected when available: sex, age, reporting date, suspected $\operatorname{drug}(s)$, indication for treatment, duration of treatment, concomitant medication, outcome of the reaction, and type of reporter. Diabetes was identified when mentioned as concurrent disease in the narrative or when an antidiabetic drug was listed as concomitant.

Sales figures expressed as the number of defined daily doses (DDD) for Sweden for the corresponding period were obtained from the MPA. The DDD is the assumed average daily dose for a drug prescribed for its main indication in adults. The number of DDDs reflects the total sales, and not for men only. The number of sold DDDs was transposed to number of DDD years, one DDD year equalling the quantity used to treat one person with one DDD daily for one year.

Using the Bayesian Confidence Propagation Neural Network (BCPNN) method, the strength of the statistical association between a suspected drug and an ADR in a database can be calculated. This analysis provides a statistical indicator, the information component (IC), which in this study was used to assess the disproportionality between the observed and the expected number of reports, given the number of reports concerning the drug and the number of reports concerning the ADR in question. ${ }^{11,12}$ The IC is a logarithmic measure, and a positive IC-value with a positive $(>0)$ lower $95 \%$ confidence limit indicates a statistically significant disproportionality. The BCPNN method has previously been described in detail $^{11}$ and has been thoroughly tested and evaluated. ${ }^{13,14}$ Moreover, the method has been found effective in identifying early drug safety signals. ${ }^{11}$ Due to the tentative nature of the dataset, the method is used for hypothesis generation rather than for hypothesis testing. In this study, the BCPNN method was applied to SWEDIS reports concerning males between 1990 and 2006.

\section{Results}

Among a total of 23,176 adverse drug reactions reported in men during the 17-year study period, 225 (1\%) reports of ED were identified. Of these, 59 (26\%) occurred during treatment with antihypertensive drugs (Table 1). Most reports were found for $\mathrm{CCBs}$ whereas thiazide diuretics were the least reported. Concomitant antidiabetic drugs were mentioned in 4 (7\%) reports. The median age was under 60 years for all ATCgroups, except for thiazide diuretics where the median age was 65 . All cases were reported by physicians. Hypertension 
Table I Summary of 59 spontaneously reported cases of erectile dysfunction submitted to the Swedish Medical Products Agency between 1990 and 2006 and where at least one antihypertensive drug was suspected to have caused the reaction

\begin{tabular}{|c|c|c|c|c|c|c|c|}
\hline & $\begin{array}{l}\text { Total } \\
\text { number of } \\
\text { reports } \mathbf{N}\end{array}$ & $\begin{array}{l}\text { Reports with } \\
\text { concomitant } \\
\text { antihypertensive } \\
\text { medication N (\%) }\end{array}$ & $\begin{array}{l}\text { Age years } \\
\text { median } \\
\text { (range) }\end{array}$ & $\begin{array}{l}\text { Time to onset } \\
\text { median } \\
\text { (range) }\end{array}$ & $\begin{array}{l}\text { Positive } \\
\text { dechallenge } \\
\text { N (\%) }\end{array}$ & $\begin{array}{l}\text { Indication } \\
\text { hypertension } \\
\mathbf{N}(\%)\end{array}$ & $\begin{array}{l}\text { Diabetes' } \\
\text { N (\%) }\end{array}$ \\
\hline $\begin{array}{l}\text { Beta blocking } \\
\text { agents }\end{array}$ & 12 & $2(17 \%)^{2}$ & $\begin{array}{l}55 \text { years } \\
(31-77)\end{array}$ & $\begin{array}{l}7 \text { months } \\
\text { (weeks-4 years) }\end{array}$ & $7(58 \%)$ & $6(50 \%)$ & 0 \\
\hline $\begin{array}{l}\text { Calcium channel } \\
\text { blockers }\end{array}$ & 23 & $10(43 \%)^{3}$ & $\begin{array}{l}53 \text { years } \\
(34-70)\end{array}$ & $\begin{array}{l}\text { Days } \\
\text { (I day-3 years) }\end{array}$ & $20(87 \%)$ & $20(87 \%)$ & $2(9 \%)$ \\
\hline ACE inhibitors & II & 0 & $\begin{array}{l}58 \text { years } \\
(39-63)\end{array}$ & $\begin{array}{l}5 \text { months } \\
\text { ( } 9 \text { days }-2 \text { years })\end{array}$ & $9(82 \%)$ & 7 (64\%) & $2(18 \%)$ \\
\hline $\begin{array}{l}\text { Angiotensin II } \\
\text { receptor antagonists }\end{array}$ & 9 & $2(22 \%)^{4}$ & $\begin{array}{l}53 \text { years } \\
(4 I-75)\end{array}$ & $\begin{array}{l}2 \text { weeks } \\
\text { (I week-10 months) }\end{array}$ & $5(56 \%)$ & $6(67 \%)$ & 0 \\
\hline $\begin{array}{l}\text { Thiazide } \\
\text { diuretics }\end{array}$ & 5 & I $(20 \%)^{5}$ & $\begin{array}{l}65 \text { years } \\
(60-72)\end{array}$ & $\begin{array}{l}\text { I month } \\
\text { (I day-14 months) }\end{array}$ & $3(60 \%)$ & $4(80 \%)$ & 0 \\
\hline
\end{tabular}

'Diabetes mentioned in the narratives or use of antidiabetic medication was described in the report; ${ }^{2}$ One subject had a thiazide diuretic and I subject had an angiotensin II receptor antagonists as concomitant medication; ${ }^{3}$ Two subjects had a thiazide diuretic, 4 subjects beta-antagonists, and 4 subjects ACE inhibitors as concomitant medications; ${ }^{4}$ One subject had a thiazide diuretic and one subject a beta-antagonist as concomitant medications; ${ }^{5}$ One subjects had a beta-agonist as a concomitant medication.

was listed as the indication for treatment in $43(73 \%)$ of the reports. Sixteen patients $(27 \%)$ were treated with a combination of antihypertensive drugs from different ATC-classes. In one case a beta-antagonist as well as a thiazide diuretic was reported as suspected. In this report ED started when a thiazide diuretic had been added to metoprolol, and improved when metoprolol was withdrawn. This report is represented in both the beta-antagonist group and in the thiazide group. In the remaining reports only one antihypertensive drug was reported as a suspected drug. One report describes a patient that developed ED after generic substitution with metoprolol (not represented in Table 1).

In one case, treatment was changed from felodipine to enalapril, and in another report, treatment was changed from ramipril to losartan, in both cases the change of therapy had a beneficial effect on the ED. No concomitant medication was mentioned in $15(25 \%)$ reports, whereas information on concomitant medication was missing or unknown in 9 $(15 \%)$. In the group with beta-antagonists one patient was treated concomitantly with tadalafil, a phosphodiesterase type 5 (PDE5) enzyme inhibitor, and in the ACE inhibitor group, one patient was treated with citalopram, a selective serotonin reuptake inhibitor, a drug known to be able to induce sexual dysfunction, ${ }^{15}$ both as concomitant medication (both represented in Table 1).

\section{Sales figures and disproportionality of reporting (IC-values)}

During the study period the sales figure expressed as million DDD years were highest for beta-antagonists, and lowest for ARBs (Table 2). However the reporting rate of ED per million DDD years was highest for ARBs. The first ARB in

Table 2 Observed and expected number of reports of ED and corresponding IC values with $95 \%$ confidence limits, sales and reports per million DDD-years

\begin{tabular}{llllll}
\hline & $\begin{array}{l}\text { Number of reports } \\
\text { N (expected) }\end{array}$ & IC value & $\begin{array}{l}\text { IC 95\% confidence } \\
\text { limits }\end{array}$ & $\begin{array}{l}\text { Sales (million } \\
\text { DDD-years) }\end{array}$ & $\begin{array}{l}\text { Reports/million } \\
\text { DDD-years }\end{array}$ \\
\hline Beta-antagonists & I2 (2.8) & 1.9 & $1.0-2.6$ & 7.5 & 1.6 \\
Calcium channel blockers & $23(4.0)$ & 2.4 & $1.8-2.9$ & 5.0 & 4.6 \\
ACE inhibitors & II (7.I) & 0.6 & $-0.4-1.3$ & 5.6 & 2.0 \\
Angiotensin II receptor & $9(2.1)$ & 1.9 & $0.8-2.7$ & 1.3 & 6.7 \\
antagonists & & & & \\
Thiazide diuretics & $5(0.4)$ & 2.7 & $1.2-3.7$ & 1.7 & 2.9 \\
\hline
\end{tabular}

Notes: I DDD-year $=365$ DDDs.

Abbreviations: IC, information component; DDD, defined daily doses. 
Sweden was launched in 1994 and the first report on ED was submitted in 1997, three reports were sent in 1999 and one in each year 2000, 2001, 2002, 2003 and 2005, respectively. All anti-hypertensives except ACE inhibitors demonstrate statistically significant IC-values, indicating a higher number of reports for ED than expected for these drugs. The highest IC-values were observed for CCBs and thiazide diuretics (Table 2).

\section{Discussion}

ED was reported in 1\% of all ADR-reports for male subjects during the study period. The different drug classes of antihypertensive drugs, including ARB, were all represented in the reports. As the risk to develop ED increases with age, it is noteworthy that the patients described in the reports were quite young. However, the impact of cardiovascular disease is greater among younger men with a higher probability of ED. ${ }^{16}$ According to sales statistics for 2006 from the National Board of Health and Welfare 55 to $60 \%$ of male users of thiazide diuretics, beta-antagonists, $\mathrm{CCB}$, and $\mathrm{ACE}$ inhibitors are over 65 years of age. For ARB 49\% of the male users were older than 65 (Official Statistics in Sweden, 2007 http://www. socialstyrelsen.se/Publicerat/2007/9789/2007-46-4.htm [in Swedish]). Surprisingly, a concomitant antidiabetic medication was reported in only 4 out of 59 reports $(7 \%)$. This might reflect a reporting bias in terms of an increased willingness to report ED if other risk factors such as high age or diabetes are absent. A vast majority of the patients were treated for hypertension, and ED is a known marker for hypertension. ${ }^{6}$

ARB was launched in Sweden during the study period, but we found no consistent reporting pattern, described as the Weber effect, ${ }^{17}$ for suspected ARB induced ED. This is in accordance with a previous study where no consistent reporting pattern was found for the overall reporting rate for ARB. ${ }^{18}$ ARB demonstrates the highest reporting rate of ED per million DDD years in comparison with other antihypertensive drugs studied. This must however be interpreted in the light of the overall ADR-reporting rate which was also highest for this drug group (data not shown). There was a statistically significant IC-value for all groups of antihypertensive drugs, except ACE inhibitors, indicating a higher than expected reporting rate of ED for these drugs. This is an interesting finding in view of results from other studies suggesting a positive effect of $\mathrm{ARB}$ on ED. In a study by Llisterri and co-workers a group of uncontrolled hypertensive men with sexual dysfunction was studied. After 12 weeks of treatment with losartan the reported rate of ED decreased from $75 \%$ to $12 \% .{ }^{9}$ The claim that ARB have a positive effect on ED can to a certain degree be supported by experimental data showing that the human penile cavernous muscle tone is partly balanced by angiotension II induced contraction, ${ }^{19}$ and by the suggestion that the ARB valsartan reversed ED in diabetic rats. ${ }^{20}$

A number of limitations should be acknowledged when interpreting data from spontaneous reporting systems. Information in the reports is often incomplete making it difficult or impossible to establish causal relationships between the reported event and the drug. Moreover, there is a substantial underreporting of adverse events and the reporting is not homogenous. ${ }^{21}$ The reporting rate is affected by numerous factors. The severity of the reaction, whether the reaction is a labeled ADR or not, and if the reaction is associated with a newly launched drug, has been identified as important factors for determining whether or not to report an ADR. ${ }^{22}$ In Sweden ED is listed in the SPC (http://www.fass.se [in Swedish]) for the majority of thiazide diuretics, beta-antagonists, $\mathrm{CCB}$, and ACE inhibitors. With the exception for irbersartan (Aprove ${ }^{\circledR}$; Sanofi-Aventis), ED is not listed in the SPC for ARBs and this may affect the willingness to report suspected ED for ARBs in accordance to the rules for reporting in Sweden. Moreover, there is also a possibility that ARBs are prescribed selectively to men with a probability to develop ED. A further problem with spontaneous reporting is to distinguish ADRs from the symptoms and the natural history of underlying diseases. Moreover, increased reporting of ED in association with newer drugs may be due to the fact that sexual health has been better recognized as a consequence of the introduction of PDE5 enzyme inhibitor. When treatment is available asking about sexual functions is likely to increase. ${ }^{23}$

\section{Conclusion}

All classes of major antihypertensive drugs including ARB were implicated as suspected agents in spontaneously reported cases of ED to the Swedish pharmacovigilance system. Of all reports few risk factors such as high age and diabetes were identified.The relatively high reporting of ED in association with ARB is in contrast with previous studies suggesting that ARB have no or a positive effect on ED. This discrepancy suggests that further studies are warranted on this potential adverse reaction to ARB.

\section{Disclosures}

The authors disclose no conflicts of interest. 


\section{References}

1. Hatzimouratidis K, Hatzichristou D. Sexual dysfunctions: classifications and definitions. $J$ Sex Med. 2007;4(1):241-250.

2. Dusing R. Sexual dysfunction in male patients with hypertension: influence of antihypertensive drugs. Drugs. 2005;65(6):773-786.

3. Kloner R. Erectile dysfunction and hypertension. Int J Impot Res. 2007;19(3):296-302.

4. Stadler T, Bader M, Uckert S, Staehler M, Becker A, Stief CG. Adverse effects of drug therapies on male and female sexual function. World $J$ Urol. 2006 Dec; 24(6):623-629.

5. Kloner RA, Mullin SH, Shook T, et al. Erectile dysfunction in the cardiac patient: how common and should we treat? J Urol. 2003;170 (2 Pt 2):Suppl 46-50.

6. Papatsoris AG, Korantzopoulos PG. Hypertension, antihypertensive therapy, and erectile dysfunction. Angiology. 2006;57(1):47-52.

7. Reffelmann T, Kloner RA. Sexual function in hypertensive patients receiving treatment. Vasc Health Risk Manag. 2006;2(4):447-455.

8. Fogari R, Zoppi A, Poletti L, Marasi G, Mugellini A, Corradi L. Sexual activity in hypertensive men treated with valsartan or carvedilol: a crossover study. Am J Hypertens. 2001;14(1):27-31.

9. Llisterri JL, Lozano Vidal JV, Aznar Vicente J, et al. Sexual dysfunction in hypertensive patients treated with losartan. Am J Med Sci. 2001;321(5):336-341.

10. Della Chiesa A, Pfiffner D, Meier B, Hess OM. Sexual activity in hypertensive men. J Hum Hypertens. 2003;17(8):515-521.

11. Bate A, Lindquist M, Edwards IR, et al. A Bayesian neural network method for adverse drug reaction signal generation. Eur J Clin Pharmacol. 1998;54(4):315-321.

12. Bate A, Lindquist M, Orre R, Edwards IR, Meyboom RH. Data-mining analyses of pharmacovigilance signals in relation to relevant comparison drugs. Eur J Clin Pharmacol. 2002;58(7):483-490.

13. van Puijenbroek EP, Bate A, Leufkens HG, Lindquist M, Orre R, Egberts AC. A comparison of measures of disproportionality for signal detection in spontaneous reporting systems for adverse drug reactions. Pharmacoepidemiol Drug Saf. 2002;11(1):3-10.
14. Lindquist M, Edwards IR, Bate A, Fucik H, Nunes AM, Stahl M. From association to alert - a revised approach to international signal analysis. Pharmacoepidemiol Drug Saf. 1999;8 Suppl 1:S15-S25.

15. Rosen RC, Marin H. Prevalence of antidepressant-associated erectile dysfunction. J Clin Psychiatry. 2003;64 Suppl 10:5-10.

16. Grover SA, Lowensteyn I, Kaouache M, et al. The prevalence of erectile dysfunction in the primary care setting: importance of risk factors for diabetes and vascular disease. Arch Intern Med. 2006;166(2): 213-219.

17. Wallenstein EJ, Fife D. Temporal patterns of NSAID spontaneous adverse event reports: the Weber effect revisited. Drug Saf. 2001;24(3):233-237.

18. McAdams MA, Governale LA, Swartz L, Hammad TA, Dal Pan GJ. Identifying patterns of adverse event reporting for four members of the angiotensin II receptor blockers class of drugs: revisiting the Weber effect. Pharmacoepidemiol Drug Saf. 2008;17(9):882-889.

19. Becker AJ, Uckert S, Stief CG, et al. Possible role of bradykinin and angiotensin II in the regulation of penile erection and detumescence. Urology. 2001;57(1):193-198.

20. Chen Y, Li SX, Yao LS, Wang R, Dai YT. Valsartan treatment reverses erectile dysfunction in diabetic rats. Int J Impot Res. 2007;19(4): 366-370.

21. Alvarez-Requejo A, Carvajal A, Begaud B, Moride Y, Vega T, Arias LH. Under-reporting of adverse drug reactions. Estimate based on a spontaneous reporting scheme and a sentinel system. Eur J Clin Pharmacol. 1998;54(6):483-488.

22. Ekman E, Backstrom M. Attitudes among hospital physicians to the reporting of adverse drug reactions in Sweden. Eur J Clin Pharmacol. 2009;65(1):43-46.

23. Tomlinson $\mathrm{J}$. $\mathrm{ABC}$ of sexual health: taking a sexual history. $B M J$ 1998;317(7172):1573-1576.
Drug, Healthcare and Patient Safety

\section{Publish your work in this journal}

Drug, Healthcare and Patient Safety is an international, peer-reviewed open-access journal exploring patient safety issues in the healthcare continuum from diagnostic and screening interventions through to treatment, drug therapy and surgery. The journal is characterized by the rapid reporting of reviews, original research, clinical, epidemiological and

\section{Dovepress}

post-marketing surveillance studies, risk management, health literacy and educational programs across all areas of healthcare delivery. The manuscript management system is completely online and includes a very quick and fair peer-review system. Visit http://www.dovepress.com/ testimonials.php to read real quotes from published authors. 